\title{
Short-Term Exercise In Mice Increases Tibial Post-Yield Mechanical Properties While Two Weeks of Latency Following Exercise Increases Tissue-Level Strength
}

\author{
Joseph M. Wallace (jmwallac@umich.edu) ${ }^{1}$ \\ Michael S. Ron (mron@umich.edu) ${ }^{2}$ \\ David H. Kohn (dhkohn@umich.edu) $)^{1,3}$
}

The University of Michigan, Departments of ${ }^{1}$ Biomedical Engineering, ${ }^{2}$ Mechanical Engineering and ${ }^{3}$ Biologic and Materials Sciences; Ann Arbor, MI

For Resubmission to: Calcified Tissue International

CTI-08-0176.R1

\section{Corresponding Author:}

David H. Kohn, Ph.D.

University of Michigan

Department of Biologic \& Materials Sciences

1011 N. University Ave.

Ann Arbor, MI 48109-1078

Ph: (734) 764-2206

Fax: (734) 647-2110

E-mail: dhkohn@umich.edu

\section{Funding Sources:}

DoD/US Army DAMD17-03-1-0556

NIH T32-DE07057

NIH IPA Agreement

Regenerative Sciences Training Grant R90-DK071506

Running Title: Enhanced Post-Yield Properties with Exercise, Increased Tissue Strength With Latency

Keywords: running, mechanical properties, histomorphometry, extracellular matrix

Author's accepted manuscript of the final version published as:

Wallace JM, Ron MS, Kohn DH. Short-Term Exercise in Mice Increases Tibial Post-Yield Mechanical Properties

While Two Weeks of Latency Following Exercise Increases Tissue-Level Strength. Calcif Tissue Int. 2009 Apr 1;84(4):297-304. http://dx.doi.org/10.1007/s00223-009-9228-8 


\title{
Enhanced Post-Yield Properties with Exercise, Increased Tissue Strength With Latency
}

\begin{abstract}
We have previously shown that exercise during growth increases post-yield deformation in C57BL6/129 (B6;129) male tibiae at the expense of reduced pre-yield deformation and structural and tissue strength. Other research in the literature indicates that increased mineral, cross-sectional geometry and structural strength due to exercise can be maintained or increased after exercise ends for as long as 14 weeks. It was therefore hypothesized that after our exercise protocol ends, effects of exercise on mechanical properties would persist, resulting in increased post-yield behavior and rescued strength versus age-matched control mice. Beginning at 8 weeks of age, exercise consisted of running on a treadmill (30 min/day, $12 \mathrm{~m} / \mathrm{min}, 5^{\circ}$ incline) for 21 consecutive days. At the end of running and 2 weeks later, in the cortical bone of the tibial mid-diaphyses of B6;129 male mice, changes due to exercise and latency following exercise were assayed by mechanical tests and analyses of cross-sectional geometry. Exercise increased structural post-yield deformation compared with weight-matched control mice, without changes in bone size or shape, suggesting that exercised-induced changes in pre-existing bone quality were responsible. Over the two week latency period, no growth related changes were noted in control mice, but exercise-induced changes resulted in increased tissue stiffness and strength versus mice sacrificed immediately after exercise ended. Our data indicate that periods of exercise followed by latency can alter strength, stiffness and ductility of bone independent of changes in size or shape, suggesting that exercise may be a practical way to increase the quality of the bone extracellular matrix.
\end{abstract}




\section{Enhanced Post-Yield Properties with Exercise, Increased Tissue Strength With Latency}

\section{INTRODUCTION}

Exercise-based mouse [1-5] and rat [6-9] models have almost universally shown a link between exercise and increased bone formation, resulting in increased bone size and bone mass and maintenance or increase of mechanical properties, thus supporting Wolff's law [10]. We recently demonstrated that 21 consecutive days of moderate intensity running, considerably shorter than most exercise models, significantly increased structural post-yield deformation in the tibial diaphyses of male C57BL6/129 mice [11]. Post-yield behavior in bone is important when assessing the clinical relevance of an exercise model, as post-yield and failure deformation are measurements of how well the overall structure is able to resist a catastrophic failure when the bone is deformed. Thought of in another way, post-yield behavior is a measure of the bone's ability to contend with damage that accrues with use. However, increased post-yield deformation came at the expense of reduced structural pre-yield deformation as well as structural and tissue-level strength [11]. Because tissue-level properties were changed with exercise, and properties at the tissue-level are independent of bone size, increased post-yield properties and decreased pre-yield behavior were attributed to exercise-induced changes in tissue quality.

Mice in our previous study were sacrificed 3 days after the termination of running. Others have shown that increased mineral and cross sectional geometry as well as increased structural strength due to exercise can be maintained or increased after exercise ends, compared with age-matched control rats and rats sacrificed immediately after exercise stopped [12, 13]. This continuation of the effects of exercise is similar to changes noted in the osteotomy gap during the consolidation period following distraction osteogenesis (DO). DO models indicate that 14 days of consolidation is enough for mineralized bone to fill in the osteotomy gap [14-16]. It is therefore hypothesized that after short-term moderate intensity exercise ends, mechanical 


\section{Enhanced Post-Yield Properties with Exercise, Increased Tissue Strength With Latency}

changes that occurred in the bones during exercise will persist and new mechanical changes will occur resulting in a rescue or increase in strength versus age-matched control mice.

At 11 (at the end of 21 consecutive days of exercise) and 13 weeks of age (2 weeks later), in the cortical bone of the tibial mid-diaphyses of C57BL6/129 male mice, changes due to exercise and a latency period following exercise were assayed by four-point bending mechanical tests to determine mechanical properties at the whole bone (structural) and tissue levels, as well as by analyses of bone cross-sectional geometry. 


\section{Enhanced Post-Yield Properties with Exercise, Increased Tissue Strength With Latency}

\section{MATERIALS AND METHODS}

Animals and Treatment

All animal procedures were performed at the University of Michigan with University Committee on Use and Care of Animals (UCUCA) approval (UCUCA animal approval protocol \#8518). To determine proper sample sizes for detecting effects of exercise and latency time, power calculations were performed based on measured differences and standard deviations in geometric and mechanical properties in C57BL6/129 (B6;129) male mice due to running on a treadmill [11] using a value of $\alpha=0.05$ and a power (1- $\beta$ ) of 0.80 [17]. To be able to detect differences in primary outcome measures of interest (cortical width and bone areas, structurallevel and tissue-level strength and deformation, stiffness and modulus of elasticity), a sample size of $n=15$ was used for each group.

Sixty B6;129 male mice were purchased at 5 weeks of age (The Jackson Laboratories; Bar Harbor, ME). Animals were housed in standard cages and given access to a standard diet, water and cage activity ad libitum. On the first day of the study (Day 1, 8 weeks of age), mice

were randomly assigned to 1 of 4 body weight-matched groups (11 week control, 11wc; 11 week exercise, 11we; 13 week control, 13wc; 13 week exercise; 13we). Control mice remained confined to cages for the duration of the study. Exercise consisted of running on a treadmill (12 meters/minute at a $5^{\circ}$ incline) for 30 minutes/day, 7 days/week for 21 consecutive days (Columbus Instruments, Model 1055M, Columbus, OH)[11]. Each lane of the treadmill was equipped with an adjustable-amperage (0-1.5 mA) shock grid at the rear of the belt to stimulate each mouse to run independently of all others. By the end of the second day of the experiment, all mice were running without the need of shock stimulation. One day following the end of the exercise regimen (Day 22), 11wc and 11we mice were sacrificed by $\mathrm{CO}_{2}$ inhalation, at which time the left tibia of each animal was harvested, stripped of soft tissue and stored at $4^{\circ} \mathrm{C}$ in a 


\section{Enhanced Post-Yield Properties with Exercise, Increased Tissue Strength With Latency}

$\mathrm{Ca}^{2+}$-buffered saline solution for mechanical testing within 24 hours. The 13wc and 13we mice were sacrificed 14 days later on Day 36, and the left tibiae were treated in this same manner. Body mass was measured in all mice on Day 19. At the time of sacrifice (Day 22 for the 11 week groups, Day 36 for the 13 week groups) body mass was measured in all mice.

\section{Mechanical Testing}

Left tibiae were brought to room temperature before testing and were kept hydrated in calcium-buffered saline until the test was complete. Before testing, the length of each tibia was measured from the most proximal portion of the tibial plateau to the most distal portion of the medial malleolus using digital calipers accurate to $0.01 \mathrm{~mm}$ (Mitutoyo, Aurora, IL). Bones were tested in the medial-lateral (ML) direction (medial surface in tension) in four-point bending (Admet eXpert 450 Universal Testing Machine; Norwood, MA). The fibula was carefully removed from each bone using a scalpel and the bones were positioned such that the most proximal location of the tibia-fibula junction (TFJ) was lined up with the outside edge of one loading roller. The bones were then monotonically tested to failure in displacement control at a rate of $0.025 \mathrm{~mm} / \mathrm{sec}$. Load and deflection were recorded, from which structural strength (yield and ultimate forces), stiffness (the slope of the linear portion of the force vs. displacement curve) and deformation (yield deformation, post-yield deformation and total deformation) were derived at the whole bone level $[11,18]$. After testing, the fractured halves of each bone were placed in $70 \%$ ethanol.

Bones were visually monitored during testing and the point of fracture initiation was noted. Because fractures often propagated at an angle across the bone (i.e. oblique fractures), the half of the fractured bone containing both the fracture initiation site and a full planar section of bone transverse to that site was processed for histology and sectioned as described below (see 


\section{Enhanced Post-Yield Properties with Exercise, Increased Tissue Strength With Latency}

histomorphometry section). The jagged edge of the bone adjacent to the fracture site was trimmed off, and a $150 \mu \mathrm{m}$ thick planar section was obtained (see histomorphometry section below). Cross-sectional images at the fracture site were acquired (Nikon Eclipse TE 300) and analyzed using digital analysis software (Image Pro-Plus v4.5, Matlab v6.0). A subset of geometric properties at the fracture site was obtained for the purposes of normalizing structurallevel mechanical data and calculating predicted tissue-level properties (bending moment of inertia about the anterior-posterior (AP) axis, $\mathrm{I}_{\mathrm{AP}}$, and the distance from the centroid to the tensile surface of the bone, c). For the purposes of determining the effects of exercise and latency time on cross-sectional properties, a full set of geometric properties was determined at a standard site (see histomorphometry section below). Together with the load and deflection data, $\mathrm{I}_{\mathrm{AP}}$ and c were used to map force and displacement (structural level properties dependent on bone structural organization) into stress and strain (predicted tissue level properties) from standard beam-bending equations for four-point bending:

$$
\text { Stress }=\sigma=\frac{F a c}{2 I_{A P}}(M P a) \quad \text { Microstrain }=\mu \varepsilon=\frac{6 c d}{a(3 L-4 a)} \times 10^{6}
$$

In these equations, $\mathrm{F}$ is the force, $\mathrm{d}$ is the displacement, $\mathrm{a}$ is the distance from the support to the inner loading point $(3 \mathrm{~mm})$ and $\mathrm{L}$ is the span between the outer supports $(9 \mathrm{~mm})$. The yield point was calculated using the $0.2 \%$ offset method based on the stress-strain curve [19]. The modulus of elasticity was calculated as the slope of the linear portion of the stress-strain curve. Deriving mechanical properties at the tissue-level using beam bending theory is only valid in the pre-yield regime [19]. Therefore, post-yield and failure strain are not reported. 


\section{Enhanced Post-Yield Properties with Exercise, Increased Tissue Strength With Latency}

\section{Static Histomorphometry}

Following mechanical testing, both fractured halves of all left tibiae were dehydrated in graded ethanol (70\%, 80\%, 95\%, 100\%), cleared in xylene and Clear-Rite 3 (a blend of isoparaffinic aliphatic hydrocarbons, Richard-Allen Scientific; Kalamazoo, MI) and infiltrated in a liquid methylmethacrylate monomer (Koldmount ${ }^{\mathrm{TM}}$ Cold Mounting Liquid, Mager Scientific). The bones were then embedded in poly methylmethacrylate (Koldmount ${ }^{\mathrm{TM}}$ Cold Mounting Kit, Mager Scientific). Using a low-speed sectioning saw (South Bay Technology, Model 650; San Clemente, CA) with a diamond wafering blade (Mager Scientific), sections approximately 150 $\mu \mathrm{m}$ thick were made at the fracture site (to normalize mechanical properties as described in the Mechanical Testing Section above) or at a standard site just proximal to the TFJ for static histomorphometry (sections were located an average distance of $6.85 \pm 0.83 \mathrm{~mm}$ from the distal end of the bone). Histomorphometric sections were hand ground and polished to a final thickness of between 50 and $75 \mu \mathrm{m}$ using wet silicon carbide abrasive discs.

Sections were imaged at a magnification of 200X (Nikon Eclipse TE 300) and analyzed using digital analysis software (Image Pro-Plus v4.5). For static histomorphometry, crosssectional geometric properties were determined (total cross-sectional area, cortical area, marrow area, AP width, ML width, average cortical thickness and moments of inertia about the AP $\left(\mathrm{I}_{\mathrm{AP}}\right)$ and $\mathrm{ML}\left(\mathrm{I}_{\mathrm{ML}}\right)$ axes). 
Statistical Analysis

All data are presented as mean \pm standard error of the mean (SEM). Statistical analyses were performed on body mass, and all geometric and mechanical properties using a two-way ANOVA checking for the main effects of exercise and time, followed by post-hoc StudentNewman-Keuls tests (Sigma Stat 3.0, Jandel Scientific). A value of $\mathrm{p}<0.05$ was considered significant. In groups which failed to exhibit normal distributions or equal variance, MannWhitney rank sum tests were performed. 


\section{Enhanced Post-Yield Properties with Exercise, Increased Tissue Strength With Latency}

\section{RESULTS}

Body mass (Table 1)

Between Day 1 and Day 19, the body mass of 11wc mice significantly increased $(p=0.034)$ while that of 11 we mice was unchanged. The result was that at Day 19, 11we mice weighed significantly less than $11 \mathrm{wc}$ mice $(\mathrm{p}=0.050)$. For 13 week control mice $(13 \mathrm{wc})$, there was no difference in body mass compared with 11wc mice at Day 19. In 13wc mice, there was no change in body mass between Day 1 and Day 19 or between Day 19 and Day 36. In 13we mice, there was no change in body mass between Day 1 and Day 19, but body mass was significantly increased during the latency period between Day 19 and Day 36 ( $p=0.009)$. In 13we versus 13wc mice, body mass was significantly decreased at Day 19 ( $p=0.016)$, but was not significantly different at Day 36.

\section{Cross-Sectional Geometry (Figure 1)}

There were no significant differences present in any cross-sectional geometric properties (Figure 1) or in tibial length (Table 1) in 11we versus 11wc mice or in 13we versus 13wc mice. There were also no significant differences in cross-sectional geometric properties (Figure 1), or tibial length (Table 1) between 13wc mice and 11wc mice. The absence of cross-sectional and longitudinal geometric changes indicates a lack of growth-related changes in these mice. A comparison between 13we mice and 11we mice shows that 13we mice had significantly smaller marrow area compared with 11we mice ( $\mathrm{p}=0.041$, Figure $1 \mathrm{~A})$, indicating endocortical contraction following the termination of exercise. 


\section{Enhanced Post-Yield Properties with Exercise, Increased Tissue Strength With Latency}

Structural-level mechanical properties (Figure 2)

At the structural level, exercise significantly increased post-yield deformation in 11we versus 11 wc mice ( $p=0.010$, Figure $2 \mathrm{~A}$ ), and deformation to yield was significantly decreased ( $p=0.028$, Figure 2A), but there were no differences in yield force, ultimate force or stiffness. There were no differences in structural-level mechanical properties in 13we versus 13wc mice, 13wc versus 11wc mice or 13we versus 11we mice (Figure 2). These data indicate that while exercise impacted structural-level mechanical properties, there were no changes with growth or with the post-exercise latency period.

Tissue-level mechanical properties (Figure 3)

Pre-yield tissue level mechanical properties were not different in 11we versus 11wc mice or in 13we versus 13wc mice. No tissue-level properties differed significantly in 13wc versus 11wc mice, indicating no changes with growth. 13we mice had significantly increased yield stress ( $p=0.049$, Figure 3B), ultimate stress $(p=0.044$, Figure $3 B)$ and modulus $(p=0.010$, Figure 3C) versus 11we mice, suggesting that these properties continued to change in the post-exercise latency period. 


\section{Enhanced Post-Yield Properties with Exercise, Increased Tissue Strength With Latency}

\section{DISCUSSION}

Following three weeks of exercise, the tibiae of male B6;129 mice exhibited significantly increased post yield deformation but decreased pre-yield deformation (Figure 2A), consistent with a previous experiment using the same exercise protocol [11]. Mechanical changes came in the absence of changes in cross-sectional size or shape (Figure 1), suggesting that alterations in the quality of the tissue versus changes in bone mass were responsible.

There were no differences in any properties in the 13we versus 13wc mice, meaning that the significant decrease in pre-yield deformation noted in 11we versus 11 wc mice was compensated for during the latency period (Figure 2A). There were no growth related changes in tibial length, geometric or mechanical properties in control mice in the two weeks following the end of exercise (13wc versus 11wc, Table 1, Figures 1-3). However, tissue-level strength (Figure 3B) and stiffness (Figure 3C) were significantly greater in 13we mice versus 11we mice, indicating that exercise altered the way these properties changed during the latency period in these mice. Further, marrow area was significantly smaller in 13we mice versus 11we mice, indicating endocortical contraction after exercise was terminated. Changes following the termination of running could be the result of latency, or continuing effects of exercise. Given more time to adapt following the end of running (in excess of the 2 weeks investigated here), the exercise-induced changes in both pre-yield and post-yield mechanical properties may result in greater differences versus age-matched control mice. By sacrificing at different times following the termination of exercise, the evolution of these changes could be investigated.

Cross-sectional geometric size and shape (Figure 1) were not altered by exercise or growth. Since cross-sectional size is indicative of the quantity of bone present and moment of inertia is representative of the distribution of that bone, the mechanical changes that occurred 


\section{Enhanced Post-Yield Properties with Exercise, Increased Tissue Strength With Latency}

during exercise were likely driven by differences in the quality of the pre-existing extracellular matrix (ECM).

Exercise initially increased post-yield behavior at the structural-level. Since post-yield properties of bone are primarily dictated by the organic portion of the ECM [20-24], and crosssectional size and shape did not change with loading, exercise likely exerted its initial effects through changes in the organic compartment of pre-existing bone. In fact, recent studies utilizing Raman microspectroscopy to probe the chemical composition of bone indicate that exercise increases the overall maturity of collagen cross-linking in the tibiae of male mice of this background strain [25].

The 13we mice had significantly greater tissue-level modulus, yield stress and ultimate stress compared with 11we mice (Figure 3), properties that suggest the mineral was altered after exercise was terminated [18, 20, 24, 26]. However, mineral composition and density were not measured in the current study, so this hypothesis cannot be specifically addressed.

This short-term exercise regimen can increase the expression of a number of bone proteins including type I collagen and signaling molecules (TGF $\beta$, BMP2 and BMP4) [27]. It is possible that changes in tissue quality that are ultimately impacting the mechanical integrity of the bones in this study are driven by both local cell-mediated [28]and non-cell-mediated processes [29-33].

It has been known for many years that mechanical stimulation can influence bone through accrual of bone mass and changes in structural architecture [10, 34]. However, it is becoming increasingly clear that exercise can influence the quality of the bone ECM independent of changes in bone size, leading to increased mechanical integrity[25]. The current study is consistent with the idea that exercise followed by latency may be practical way to alter the quality of bone [35-38] and warrants further investigation. A limitation of this study is that a 


\section{Enhanced Post-Yield Properties with Exercise, Increased Tissue Strength With Latency}

continuous exercise group (i.e. 5 weeks of exercise beginning at 8 weeks of age), which could have helped in clarifying the effects of latency, was not used.

The 21 days of exercise used in the current study is shorter in duration than most other exercise protocols $[2,39]$. A single bout of mechanical loading may be enough to induce a response [40], but that response may become saturated [41]. It may be possible to decrease the duration of our exercise protocol even further and still elicit changes in mechanical integrity.

In summary, data from this study suggest that independent of changes in bone size or shape, exercise increased mechanical properties reflecting changes in ECM quality. Over the two week latency period following exercise, exercise-induced changes resulted in increased tissue-level stiffness and strength versus mice sacrificed immediate after exercise ended. Increased stiffness and strength likely occurred through alterations in mineral chemistry and/or density $[25,42]$. The current study suggests that exercise followed by latency may be a practical way to increase the quality of the bone extracellular matrix, a concept that requires further investigation. 


\section{Figure Titles and Legends}

\section{Figure 1}

Title: Cross-Sectional Geometric Properties in the Tibial Diaphyses

Legend: There were no differences in any cross-sectional geometric properties in 11we versus

11wc mice or in 13we versus 13wc mice. No properties changed with growth in control mice between 11 and 13 weeks of age. In 13we mice compared with 11we mice, there was a significant decrease in marrow area. Data are presented as mean \pm SEM.

Figure 2

Title: Structural-Level Mechanical Properties in the Tibial Diaphyses

Legend: There was a significant decrease in elastic deformation to yield (A) and a significant increase in post-yield deformation (A) in 11we mice versus 11wc. No properties changed with growth in control mice between 11 and 13 weeks of age. There were no differences in any structural-level mechanical properties in 13we mice versus 13wc mice or versus 11 we mice. Data are presented as mean \pm SEM.

\section{Figure 3}

Title: Tissue-Level Mechanical Properties in the Tibial Diaphyses

Legend: No properties were different in 11we mice versus 11wc mice or in 13we mice versus

13wc mice. No properties changed with growth in control mice between 11 and 13 weeks of age. In 13we mice compared with 11we mice, there was a significant increase in yield stress (B), ultimate stress (B) and modulus (C). Data are presented as mean \pm SEM. 
Figure 1
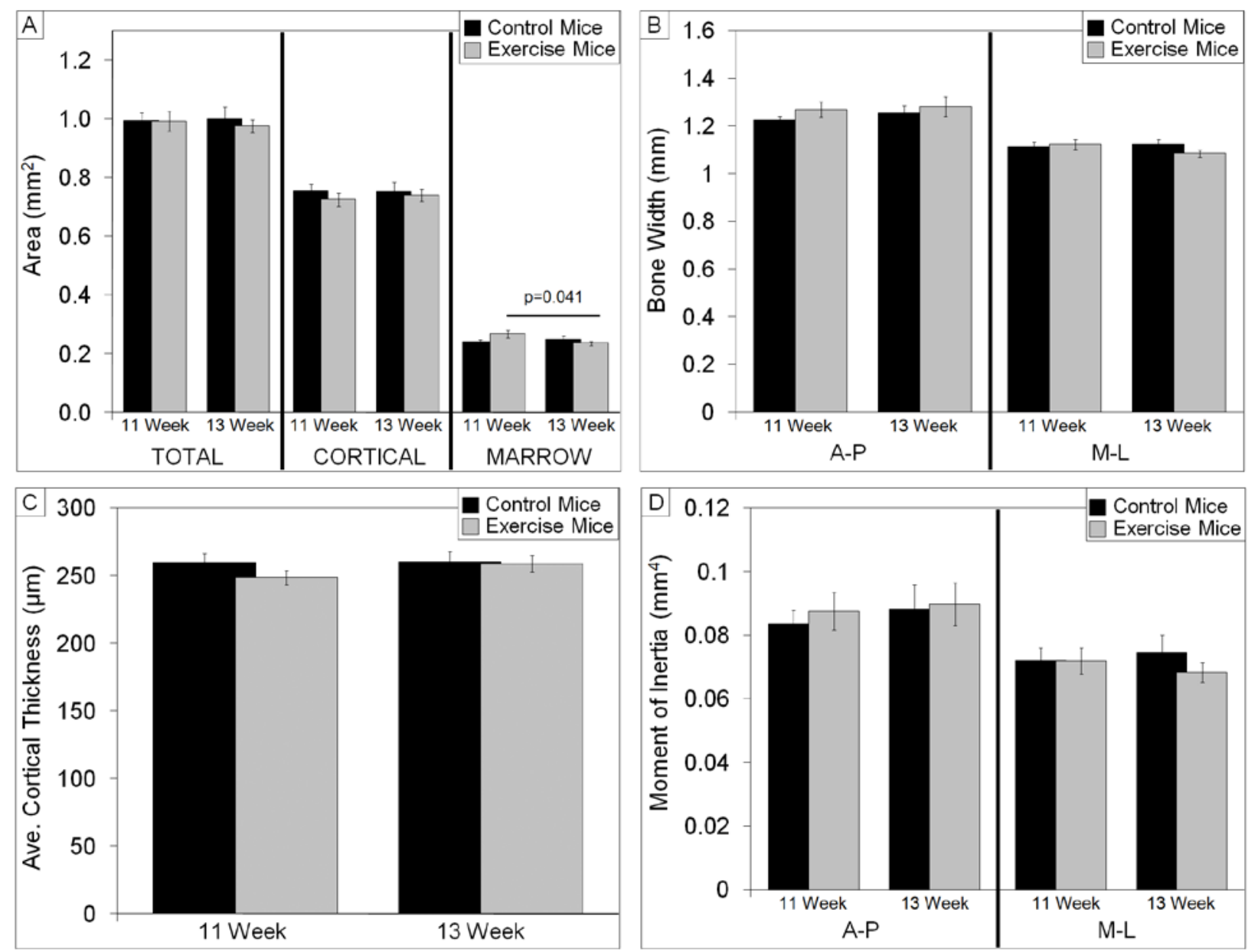
Figure 2

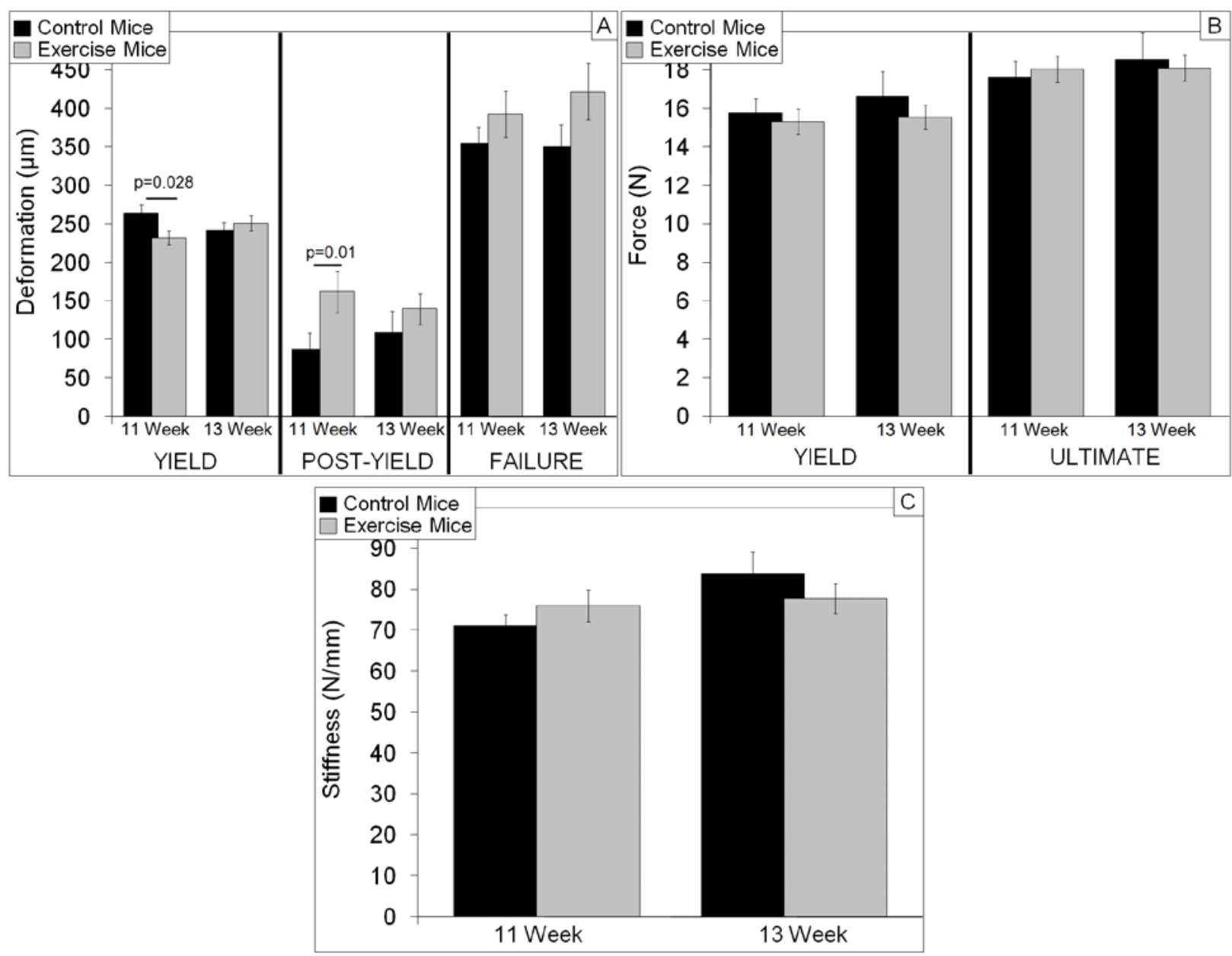


Figure 3

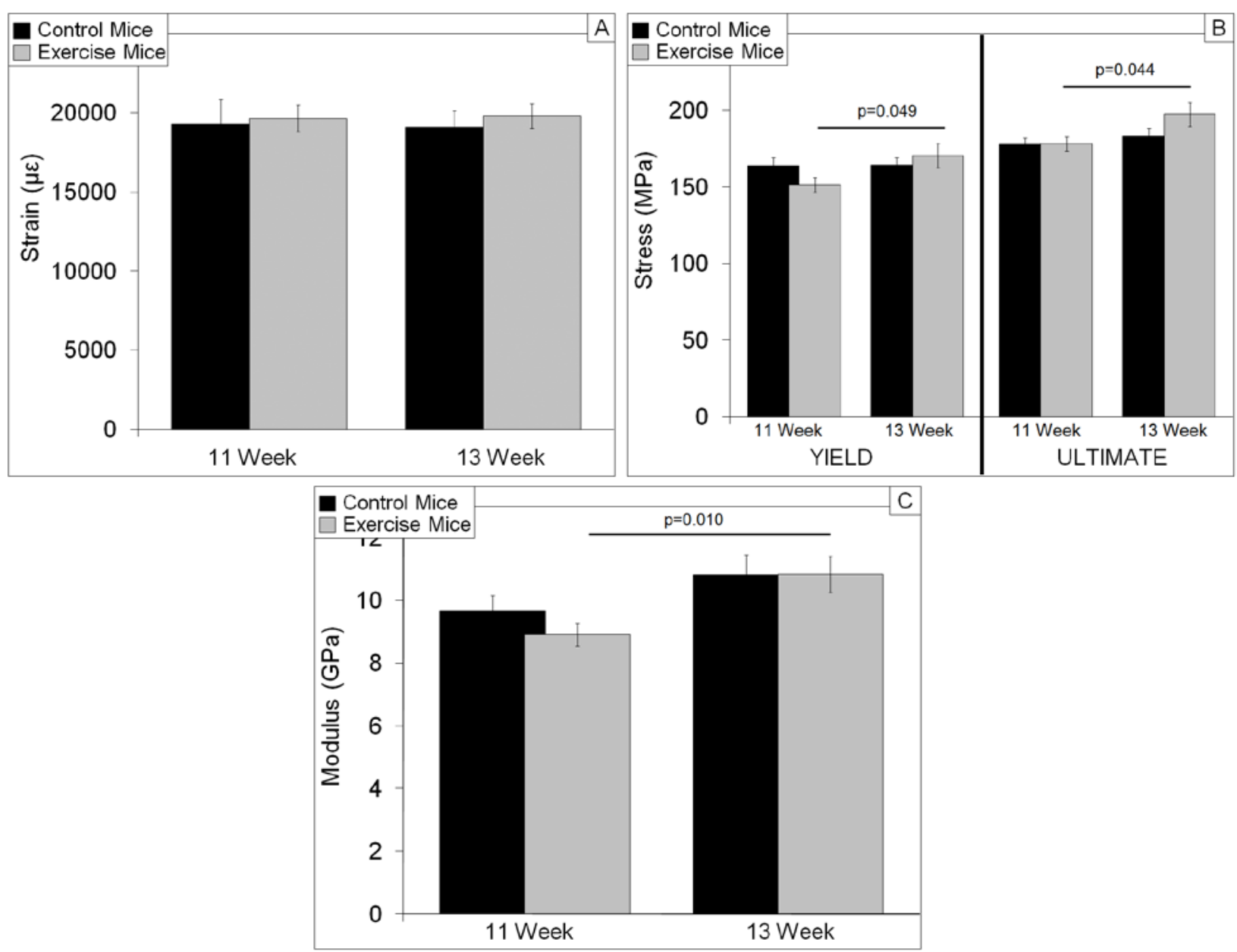




\section{Enhanced Post-Yield Properties with Exercise, Increased Tissue Strength With Latency}

\section{REFERENCES}

(1) Mori T, Okimoto N, Sakai A, Okazaki Y, Nakura N, Notomi T, Nakamura T (2003) Climbing exercise increases bone mass and trabecular bone turnover through transient regulation of marrow osteogenic and osteoclastogenic potentials in mice. J.Bone Miner.Res. 18:2002-2009

(2) Wu J, Wang XX, Higuchi M, Yamada K, Ishimi Y (2004) High bone mass gained by exercise in growing male mice is increased by subsequent reduced exercise. J.Appl.Physiol. 97:806-810

(3) Hoshi A, Watanabe H, Chiba M, Inaba Y (1998) Bone density and mechanical properties in femoral bone of swim loaded aged mice. Biomed.Environ.Sci. 11:243-250

(4) Gordon KR, Levy C, Perl M, Weeks OI (1994) Experimental perturbation of the development of sexual size dimorphism in the mouse skeleton. Growth Dev.Aging 58:95-104

(5) Kodama Y, Umemura Y, Nagasawa S, Beamer WG, Donahue LR, Rosen CR, Baylink DJ, Farley JR (2000) Exercise and mechanical loading increase periosteal bone formation and whole bone strength in C57BL/6J mice but not in C3H/Hej mice. Calcif.Tissue Int. 66:298306

(6) Umemura Y, Ishiko T, Yamauchi T, Kurono M, Mashiko S (1997) Five jumps per day increase bone mass and breaking force in rats. J.Bone Miner.Res. 12:1480-1485

(7) Iwamoto J, Yeh JK, Aloia JF (2000) Effect of deconditioning on cortical and cancellous bone growth in the exercise trained young rats. J.Bone Miner.Res. 15:1842-1849

(8) Notomi T, Okimoto N, Okazaki Y, Tanaka Y, Nakamura T, Suzuki M (2001) Effects of tower climbing exercise on bone mass, strength, and turnover in growing rats. J.Bone Miner.Res. 16:166-174

(9) Huang TH, Lin SC, Chang FL, Hsieh SS, Liu SH, Yang RS (2003) Effects of different exercise modes on mineralization, structure, and biomechanical properties of growing bone. J.Appl.Physiol. 95:300-307

(10) Wolff J (1892) Das gesetz der transformation der knochen. August Hirschwald, Berlin

(11) Wallace JM, Rajachar RM, Allen MR, Bloomfield SA, Robey PG, Young MF, Kohn DH (2007) Exercise-Induced Changes in the Cortical Bone of Growing Mice are Bone- and Gender-Specific. Bone 40:1120-1127

(12) Singh R, Umemura Y, Honda A, Nagasawa S (2002) Maintenance of bone mass and mechanical properties after short-term cessation of high impact exercise in rats. Int.J.Sports Med. 23:77-81 


\section{Enhanced Post-Yield Properties with Exercise, Increased Tissue Strength With Latency}

(13) Pajamaki I, Kannus P, Vuohelainen T, Sievanen H, Tuukkanen J, Jarvinen M, Jarvinen TL (2003) The bone gain induced by exercise in puberty is not preserved through a virtually lifelong deconditioning: a randomized controlled experimental study in male rats. J.Bone Miner.Res. 18:544-552

(14) Tay BK, Le AX, Gould SE, Helms JA (1998) Histochemical and molecular analyses of distraction osteogenesis in a mouse model. J.Orthop.Res. 16:636-642

(15) Carvalho RS, Einhorn TA, Lehmann W, Edgar C, Al-Yamani A, Apazidis A, Pacicca D, Clemens TL, Gerstenfeld LC (2004) The role of angiogenesis in a murine tibial model of distraction osteogenesis. Bone 34:849-861

(16) Isefuku S, Joyner CJ, Simpson AH (2000) A murine model of distraction osteogenesis. Bone 27:661-665

(17) Moore DS, McCabe GP (2003) Introduction to the Practice of Statistics. 4W.H. Freeman \& Company, New York, NY

(18) Wallace JM, Rajachar RM, Chen XD, Shi S, Allen MR, Bloomfield SA, Les CM, Robey PG, Young MF, Kohn DH (2006) The mechanical phenotype of biglycan-deficient mice is bone- and gender-specific. Bone 39:106-116

(19) Turner CH, Burr DB (1993) Basic Biomechanical Measurements of Bone: A Tutorial. Bone 14:595-607

(20) Boskey AL, Wright TM, Blank RD (1999) Collagen and bone strength. J.Bone Miner.Res. 14:330-335

(21) Burstein AH, Zika JM, Heiple KG, Klein L (1975) Contribution of collagen and mineral to the elastic-plastic properties of bone. J.Bone Joint Surg.Am. 57:956-961

(22) Wang X, Shen X, Li X, Agrawal CM (2002) Age-related changes in the collagen network and toughness of bone. Bone 31:1-7

(23) Garnero P, Borel O, Gineyts E, Duboeuf F, Solberg H, Bouxsein ML, Christiansen C, Delmas PD (2006) Extracellular post-translational modifications of collagen are major determinants of biomechanical properties of fetal bovine cortical bone. Bone 38:300-309

(24) Viguet-Carrin S, Garnero P, Delmas PD (2006) The role of collagen in bone strength. Osteoporos.Int. 17:319-336

(25) Kohn DH, Sahar ND, Wallace JM, Golcuk K, Morris MD (2009) Exercise alters mineral and matrix composition in the absence of adding new bone. Cells Tissues Organs 189:33-37

(26) Currey JD (1988) The effect of porosity and mineral content on the Young's modulus of elasticity of compact bone. J.Biomech. 21:131-139 


\section{Enhanced Post-Yield Properties with Exercise, Increased Tissue Strength With Latency}

(27) Wallace JM (2007) Investigating the Inbred Strain-Specific Response to BiglycanDeficiency and Exercise: A Study in Genetically-Medicated Skeletal Adaptation. PhD Dissertation, University of Michigan http://hdl.handle.net/2027.42/57673

(28) Qing H, Ardeshirpour L, Dusevich V, Dallas M, Wysolmerski JJ, Bonewald LF (2008) Osteocytic Perilacunar Remodeling as a Significant Source of Calcium During Lactation. ASBMR Abstract \#M110

(29) Carden A, Rajachar RM, Morris MD, Kohn DH (2003) Ultrastructural changes accompanying the mechanical deformation of bone tissue: a Raman imaging study. Calcif.Tissue Int. 72:166-175

(30) Vaidya S, Karunakaran C, Pande B, Gupta N, Iyer R, Karweer S (1997) Pressure-induced crystalline to amorphous transition in hydroxylapatite. J.Mater.Sci. 32:3213-3217

(31) Gupta HS, Seto J, Wagermaier W, Zaslansky P, Boesecke P, Fratzl P (2006) Cooperative deformation of mineral and collagen in bone at the nanoscale. Proc.Natl.Acad.Sci.U.S.A. 103:17741-17746

(32) Wilson EE, Awonusi A, Morris MD, Kohn DH, Tecklenburg MM, Beck LW (2005) Highly ordered interstitial water observed in bone by nuclear magnetic resonance. J.Bone Miner.Res. 20:625-634

(33) Wilson EE, Awonusi A, Morris MD, Kohn DH, Tecklenburg MM, Beck LW (2006) Three structural roles for water in bone observed by solid-state NMR. Biophys.J. 90:3722-3731

(34) Carter DR, Van Der Meulen MC, Beaupre GS (1996) Mechanical factors in bone growth and development. Bone 18:5S-10S

(35) Rubin C, Xu G, Judex S (2001) The anabolic activity of bone tissue, suppressed by disuse, is normalized by brief exposure to extremely low-magnitude mechanical stimuli. FASEB J. $15: 2225-2229$

(36) Rubin C, Recker R, Cullen D, Ryaby J, McCabe J, McLeod K (2004) Prevention of postmenopausal bone loss by a low-magnitude, high-frequency mechanical stimuli: a clinical trial assessing compliance, efficacy, and safety. J.Bone Miner.Res. 19:343-351

(37) Ward K, Alsop C, Caulton J, Rubin C, Adams J, Mughal Z (2004) Low magnitude mechanical loading is osteogenic in children with disabling conditions. J.Bone Miner.Res. 19:360-369

(38) Carleton SM, Weber B, McCambridge A, Ferriera J, Brown MB, Phillips CL (2008) Impact of exercise on skeletal muscle and bone in oim mice. Matrix Biol. 27:24

(39) Wu J, Wang XX, Takasaki M, Ohta A, Higuchi M, Ishimi Y (2001) Cooperative effects of exercise training and genistein administration on bone mass in ovariectomized mice. J.Bone Miner.Res. 16:1829-1836 
(40) Forwood MR, Owan I, Takano Y, Turner CH (1996) Increased bone formation in rat tibiae after a single short period of dynamic loading in vivo. Am.J.Physiol. 270:E419-23

(41) Rubin CT, Lanyon LE (1984) Regulation of bone formation by applied dynamic loads. J.Bone Joint Surg.Am. 66:397-402

(42) Boskey AL (2003) Bone mineral crystal size. Osteoporos.Int. 14 Suppl 5:16-21 